\title{
STRATEGI NAIKAN OMZET LEWAT ONLINE
}

\author{
Syarifudin $^{1}$, Aditya Riky Nugroho ${ }^{2}$, AntaniaShintaYuwono $^{3}$, Suripto $^{4}$, SyamsulAsmedi $^{5}$ \\ S1 Akuntansi, Fakultas Ekonomi, UniversitasPamulang \\ ${ }^{1}$ dosen02336@unpam.ac.id,2'dosen02305@unpam.ac.id, ${ }^{3}$ dosen01112@unpam.ac.id, \\ ${ }^{4}$ dosen0756@unpam.ac.id, ${ }^{5}$ dosen02193@unpam.ac.id
}

\begin{abstract}
Abstrak
Pengabdian masyarakat adalah suatu kegiatan yang bertujuan membantu masyarakat tertentu dalam beberapa aktivitas tanpa mengharapkan imbalan dalam bentuk apapun. Secara umum program ini dirancang oleh berbagai universitas atau institut yang ada di Indonesia salah satunya Universitas pamulang. Untuk memberikan kontribusinyata bagi bangsa Indonesia, khususnya dalam mengembangkan kesejahteraan dan kemajuan bangsa Indonesia. Kegiatan Pengabdian Masyarakat merupakan salah satu bagian dari Tri Dharma Perguruan Tinggi. Bentuk kegiatan dalam pelaksanaan pengabdian kepada masyarakat di Desa jampang yaitu melakukan alih tehnologi dengan tema Strategi Menaikan Omzet lewat online. Dengan para pengajar dan narasumber yang dilibatkan adalah para Dosen Prodi Akuntansi dari Universitas Pamulang. Hasil Pelaksanaan PKM yang dilakukan tanggal 20,21 dan 22 September 2019 adalah menambah ilmu mereka di bidang ekonomi, terutang tentang pemasaran, para peserta kelompok ikan hias di desa Jampang sangat antusias dengan materi yang mereka dapatkan dari dosen-dosen akuntansi Universitas Pamulang. Para peserta dapat langsung mempraktikkan penjualan lewat online, Respon para peserta sangat baik dan senang karena sangat terbantu dalam pembelajaran tentang cara penjualan lewat online.
\end{abstract}

Kata kunci : Strategi Naikan Omzet lewat online.

\begin{abstract}
Community service is an activity that aims to help certain communities in several activities without expecting any form of reward. In general, this program is designed by various universities or institutes in Indonesia, one of which is Pamulang University. To make a real contribution to the Indonesian nation, especially in developing the welfare and progress of the Indonesian nation. Community Service Activities are part of the Tri Dharma of Higher Education. The form of activities in the implementation of community service in Jampang village is transferring technology with the theme of Strategies to Increase Turnover via online. The teachers and resource persons involved are the Lecturers of the Accounting Study Program from Pamulang University. The results of the PKM implementation which was carried out on 20,21 and 22 September 2019 were adding to their knowledge in the field of economics, owed about marketing, the participants of the ornamental fish group in Jampang village were very enthusiastic about the material they got from the accounting lecturers of Pamulang University, the participants can directly practice selling via online, the response of the participants was very good and happy because it was greatly helped in learning about how to sell via online.
\end{abstract}

Keywords: Online Turnover Increase Strategy. 


\section{PENDAHULUAN}

Pengembangan Desa Jampang yang merupakan desa binaan Universitas Pamulang terus diupayakan. Desa yang memiliki setu seluas 21 hektare yang menjadi lahan usaha untuk membudidaya jenis ikan hias seperti cupang, lohan, Memphis,koi dan masih banyak lagi ikan hias yang merupakan produk unggulan dan selain itu ditambah dengan beberapa jenis ikan konsumsi seperti lele, gurame dan ikan patin. Hampir sebagian besar warga Desa Jampang menjadikan budidaya ikan sebagai mata pencahariannya dengan memanfaatkan lahan sekitar dari luas setu tersebut. Kelompok tani pembudidaya ikan memiliki potensi untuk dikembangkan dan dimajukan lagi.dalam hal pemasaran produk yang dihasilkan dari budidaya ikan sudah cukup meluas, terbukti dengan adanya penjualan ikan patin ke daerah Pekan Baru dan juga daerah-daerah lain di luar Kota Bogor, termasuk penjualan ke manca negara. Namun karena keterbatasan pengetahuan dan wawasan terkait dengan perkembangan tehnologi,pemasaran produk ikan hias dan ikan konsumsi ini masih belum dikembangkan atau dipadukan dengan pemasaran online.dengan memasarkan lewat online dipastikan akan lebih banyak lagi pembeli-pembeli yang ada di seluruh
Indonesia bahkan dunia internasional, sehingga masyarakat Desa Jampang khususnya kelompok tani tersebut dapat meningkatkan omzet penjualan yang lebih banyak lagi. Menurut survei yang dilakukan oleh SWA, Indonesia merupakan terbesar kedua di dunia sebagai pengguna Facebook dan Twitter dan sangat menjanjikan bagi pemasaran online, apalagi didukung dengan kemudahan dalam memperoleh ponsel. Internet memiliki daya tarik bagi konsumen karena memiliki keunggulan misalnya kenyamanan, memiliki akses 24 jam sehari, efisiensi alternative ruang, jangkauan wilayah yang tidak terbatas. Online Marketing atau pemasaran online sebenarnya sudah dilakukan oleh pembudidaya Ikan di Desa Jampang Kecamatan Kemang Kabupaten Bogor, tapi belum optimal dalam pengelolaannya. sehingga tidak berjalan dengan baik.

Adapun tujuan dari pengabdian kepada masyarakat ini adalah untuk membantu pembudidaya ikan di daerah Jampang, Bogor dalam mengoptimalkan pemasaran atau penjualan lewat online.

\section{METODE}

Kegiatan pengabdian kepada masyarakat ini mengusung tema "Strategi Naikan Omzet 
lewat Online " dilaksanakan di Aula Setu sekitar lokasi tambak ikan berada.

Desa Jampang, Bogor, salah satu daerah di Propinsi Jawa Barat yang menghasilkan komoditi ikan hias air tawar dan ikan konsumsi berada di Kotamadya Bogor. Desa Jampang memiliki setu seluas 21 hektar yang menjadi lahan usaha para pembudidaya ikan, jenis ikan hias merupakan produk unggulan dan ditambah dengan beberapa jenis ikan konsumsi. Hampir sebagian besar warga desa Jampang menjadikan budidaya ikan sebagai mata pencahariannya dengan memanfaatkan sekitar $25 \%$ dari luas setu tersebut. Kelompok pembudidaya ikan memiliki potensi yang sangat bagus yang harus dikembangkan, namun karena keterbatasan pengetahuan, usaha mereka belum memiliki sistem pemasaran yang baik. Dan produksi ikan kelompok ini juga berpotensi besar yang harus didukung dengan pemasaran yang efektif dan efisien.

Kegiatan ini dilakukan melalui penyuluhan dan presentasi materi tentang strategi naikan omzet lewat online yang di paparkan oleh Bapak Syarmsul Asmedi, S.E.,M.M,.M.Ak, Sebelum materi yang disampaikan oleh narasumber diawali dengan penjelasan mengutarakan kendalakendala atau permasalahan yang dihadapi dalam melakukan budidaya ikan hias dan air tawar. Salah satunya sarana seperti tambak ikannya yang hanya tiang-tiang dari pinggir jaring tersebut dari bambu, jika ada angin kencang sering roboh dan ikannya terlepas. Dan kekuatan bambu hanya bertahan 6 bulan. Serta masih banyak hal lagi yang diutarakan oleh peserta, seperti tidak berkembangnya usaha kerupuk ikan dan abon yang merupakan produk turunan dari ikan yang dibudidayakan. Besar harapan peserta PKM, Universitas Pamulang dapat membantu pemasalahan yang ada lewat pemikiran-pemikiran para dosen dan narasumber serta memberikan pemahaman akan motivasi dan semangat kepada peserta, memotivasi para kelompok tani untuk bisa menghasilkan pendapatan yang besar lagi lewat online.

Kegiatan lebih rinci tertuang dalam dibawah ini : 


\begin{tabular}{|c|c|c|c|c|}
\hline No. & Tgl & Waktu & Acara & Pelaksana \\
\hline 1. & $\begin{array}{l}20-9- \\
19\end{array}$ & $\begin{array}{l}14.00- \\
16.00\end{array}$ & $\begin{array}{l}\text { Survei lapangan } \\
\text { mencari tahu } \\
\text { apa saja yang } \\
\text { dibutukan } \\
\text { dengan oleh } \\
\text { kelompok ikan }\end{array}$ & $\begin{array}{l}\text { Syarifudin, } \\
\text { S.E., M.Ak }\end{array}$ \\
\hline 2. & $\begin{array}{l}21-9- \\
19\end{array}$ & $\begin{array}{l}12.00- \\
17.00\end{array}$ & $\begin{array}{l}\text { Menyiapkan } \\
\text { materi } \\
\text { pelaksanaan, } \\
\text { sarana dan } \\
\text { prasarana } \\
\text { pelaksanaan } \\
\text { kegiatan }\end{array}$ & 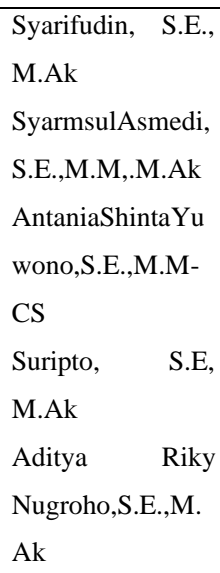 \\
\hline 3. & $\begin{array}{l}22-9- \\
19\end{array}$ & $\begin{array}{l}09.00- \\
09.15\end{array}$ & Pembukaan & $\begin{array}{l}\text { Mahasiswa } \\
\text { UniversitasPamul } \\
\text { ang }\end{array}$ \\
\hline 4. & & $\begin{array}{l}09.15- \\
10.00\end{array}$ & $\begin{array}{l}\text { Sambutan dan } \\
\text { Doa }\end{array}$ & $\begin{array}{l}\text { Syarifudin,S.E., } \\
\text { Ak., M.Ak }\end{array}$ \\
\hline 5. & & $\begin{array}{l}10.00- \\
10.45\end{array}$ & $\begin{array}{l}\text { Sambutan } \\
\text { Ketua } \\
\text { Kelompok Ikan } \\
\text { Hias }\end{array}$ & Bapak Kaman \\
\hline 6. & & $\begin{array}{l}10.45- \\
12.00\end{array}$ & Seminar & $\begin{array}{l}\text { SyarmsulAsmedi, } \\
\text { S.E.,M.M,.M.Ak }\end{array}$ \\
\hline 8. & & $\begin{array}{l}12.00- \\
13.00\end{array}$ & Isoma & \\
\hline 9. & & $\begin{array}{l}13.00- \\
13.15\end{array}$ & $\begin{array}{l}\text { Pemberian } \\
\text { Kenang- } \\
\text { Kenangan }\end{array}$ & $\begin{array}{l}\text { Syarifudin, S.E., } \\
\text { Ak., M.Ak/ } \\
\text { Bapak Kaman }\end{array}$ \\
\hline 10. & & $\begin{array}{l}13.15- \\
13.30\end{array}$ & $\begin{array}{l}\text { Kesimpulan dan } \\
\text { Penutup }\end{array}$ & $\begin{array}{l}\text { Mahasiswa } \\
\text { UniversitasPamul } \\
\text { ang }\end{array}$ \\
\hline 11. & & $\begin{array}{l}13.30- \\
14.00\end{array}$ & Foto Bersama & \\
\hline
\end{tabular}

Tabel 1. Susunan acara kegiatan

\section{HASIL DAN PEMBAHASAN}

Dalam meningkatkan penjualan masyarakat Desa Jampang sudah berupaya melakukan penjualan lewat online atau Pemasaran Online Media yang digunakan adalah Media Sosial. Adapun yang aktif digunakan adalah Instagram, Facebook, Fanpages, dan Youtube. Media Sosial yang paling aktif adalah Instagram, dengan jumlah follower mencapai 4.797 Follower yang aktif like dan comment di tiap postingan di account IG : @juragan ikan koi namun kurang dioptimalkan, terkait dengan pengetahuan tentang dunia internet masih kurang.

Kegiatan pengabdian pada masyarakat ini dilaksanakan di Desa Jampang Kab. Bogor Jawa Barat. Kegiatan ini diikuti oleh beberapa kelompok Tani Ikan hias pada tanggal 20,21,22 September 2019 pada pukul 09.00 sampai 12.00 WIB. Secara umum kegiatan ini berjalan dengan lancar dan antusiasme yang tinggi para petani kelompok ikan untuk mengikuti kegiatan tersebut. Karena mereka ingin mengetahui bagaimana cara melakukan penjualan internet dalam usaha ikan hias agar omzet dari penjualan ikan hias dapat meningkat lebih tinggi.dan jaringan pemasaran lebih luas. 
Berikut gambar-gambar kegiatan

pengabdian masyarakat para kelompok tani:

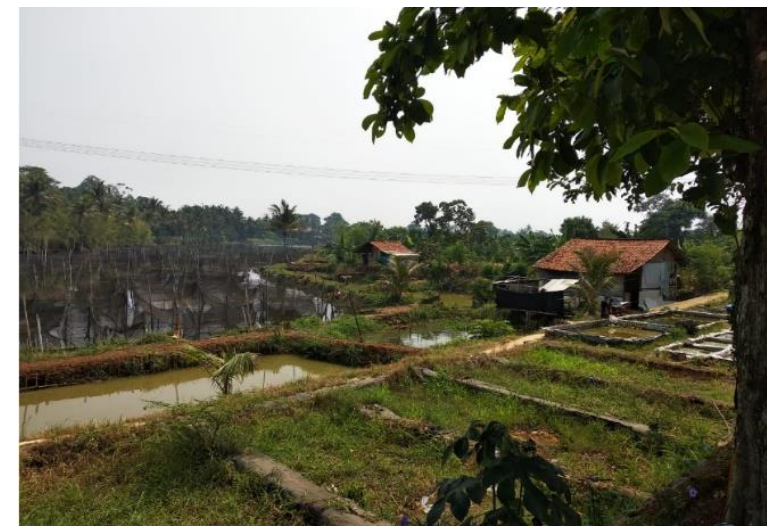

Gambar 1. Tambak Ikan desa jampang

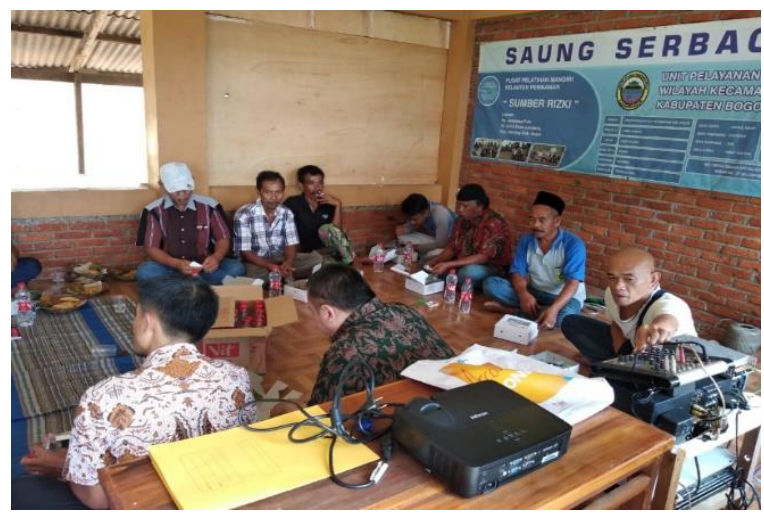

Gambar 2. Peserta kelompik tani ikan hias

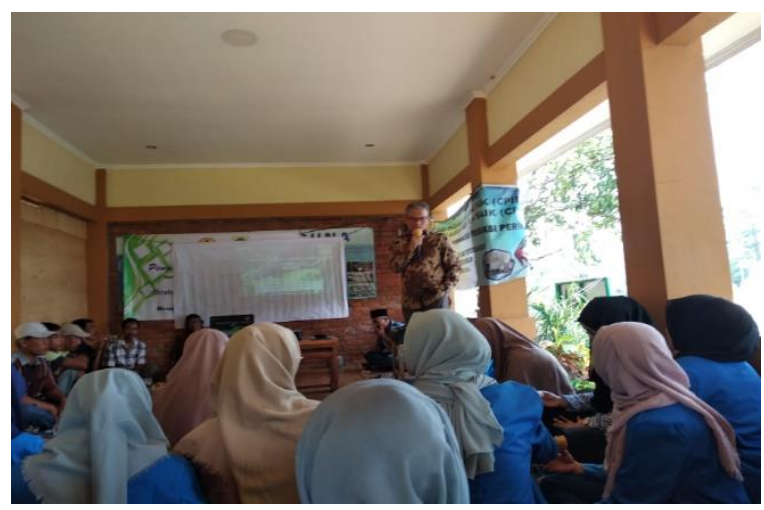

Gambar 3 Penyampaian Materi

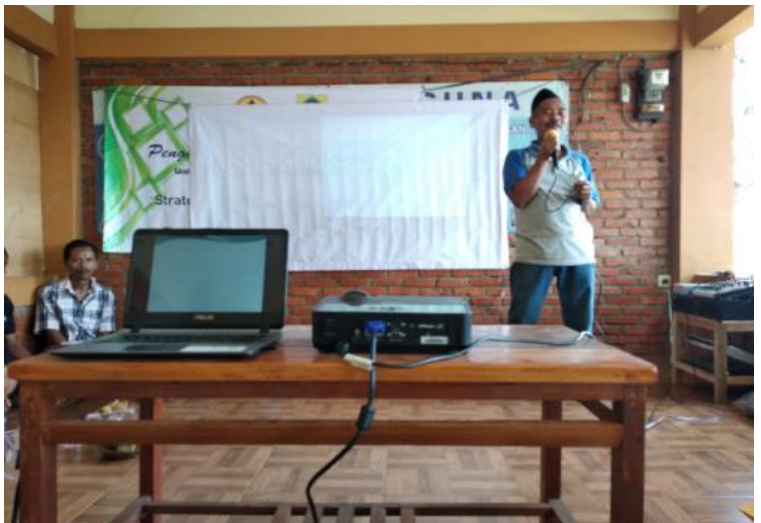

Gambar 5 . Sambutan Ketua Kelompok Tani

\section{KESIMPULAN}

Masyarakat Desa Jampang untuk budidaya ikan sudah menjadi mata pencarian,namun penjualan atau pemasaran lewat online belum maksimal masih kurang berjalan dengan baik.karena keterbatasan pengetahuan yang dimiliki masing -masing petani.

Diharapkan setelah adanya pelaksanaan kegiatan PKM ini untuk membantu para kelompok tani ikan Desa Jampang agar meningkatkan omzet penjualan dalam setiap usaha ikan hiasnya. Untuk saran kegiatan ini dalam bentuk binaan ke depannya agar tujuan dapat mewujudkan masyarakat mandiri dengan mengembangkan jaringan pemasaran di dunia internet. 


\section{REFERENSI}

Anggraini, A. A. (2008). Manajemen Keyword: Strategi Pemasaran Online Menggunakan Search Engine. Jurnal Pendidikan Akuntansi

Indonesia, 6(2).

http://www.radarbogor.id/2018/03/29/fokusgarap-kampung-wisata/

https://id.wikipedia.org/wiki/Pengabdian_m asyarakat

Hidayati, Wahyu Nurul (2019). Sosialisasi Teman Bisnis Catatan Keuangan pada Kelompok Ikan Hias di desa
Jampang, Bogor. Abdimisi vol.1 no.1

Desember 2019, 41- 42.

Kotler, P., \& Keller, K. L. (2006). Marketing management 12e. New Jersey.

Kotler, P., \& Keller, K. L. (2009). Manajemen Pemasaran (Marketing Management). Jilid I. Edisi ke, 13.

Lakutomo, G. S. (2014). Analisis Pemasaran Terhadap Bisnis Online (E-Commerce) Dalam Jaringan Sosial Internet (Doctoral dissertation, Universitas Muhammadiyah Surakarta). 